\title{
Computer-animated model of accommodation and theory of reciprocal zonular action
}

This article was published in the following Dove Press journal:

Clinical Ophthalmology

27 October 20II

Number of times this article has been viewed

\author{
Daniel B Goldberg',2 \\ 'Ophthalmology Department, Drexel \\ College of Medicine, Philadelphia, PA, \\ ${ }^{2}$ Eye Physicians, Little Silver, NJ, USA
}

Correspondence: Daniel B Goldberg

Atlantic Eye Physicians, I80 White Road,

Little Silver, NJ 07739, USA

Tel + I 7322199220

Fax + I 7322199557

Email goldbergeye@gmail.com

\begin{abstract}
This report presents a computer-animated model of the structures of accommodation based on new understanding of the anatomy of the zonular apparatus integrated with current understanding of the mechanism of accommodation. Analysis of this model suggests a new, consolidated theory of the mechanism of accommodation including a new theory of reciprocal zonular action. A three-dimensional animated model of the eye in accommodation and disaccommodation was produced in collaboration with an experienced medical animator. Current understanding of the anatomy of the zonule and the attachments of the vitreous zonule to the anterior hyaloid membrane is incomplete. Recent studies have demonstrated three components of the vitreous zonule: (1) anterior vitreous zonule (previously "hyalocapsular" zonule), which attaches the ciliary plexus in the valleys of the ciliary processes to the anterior hyaloid membrane in the region medial to the ciliary body and Weiger's ligament; (2) intermediate vitreous zonule, which attaches the ciliary plexus to the anterior hyaloid peripherally; and (3) posterior vitreous zonule, which creates a sponge-like ring at the attachment zone that anchors the pars plana zonules. The pars plana zonules attach posteriorly to the elastic choroid above the ora serrata. Analysis of the computer-animated model demonstrates the synchronized movements of the accommodative structures in accommodation and disaccommodation. Utilizing modelbased reasoning, it is shown that the posterior zonules attach to and provide traction to the anterior vitreous membrane and Weiger's ligament. This model supports the concept that the ciliary body/zonule/anterior hyaloid complex contributes to the changes in the posterior lens capsule during accommodation, supporting an extralenticular component to accommodation and demonstrating an alternative to the "vitreous support" theories. There is a reciprocal action of the anterior zonules and the posterior zonules. During ciliary body contraction, the anterior zonules lose tension while the posterior zonules stretch and exert force on the posterior lens capsule playing a role in shaping the posterior lens thickness and curvature. During ciliary body relaxation, the posterior zonules lose tension as the lens flattens and is pulled back by the increasing tension of the anterior zonules.
\end{abstract}

Keywords: zonule, posterior zonule, vitreous zonule, accommodation, mechanism of accommodation, theory of accommodation, model of accommodation, animated model of accommodation

\section{Introduction}

After more than 200 years of scientific research and debate, the technologic advances and research of the past decade have provided the necessary basis to solve some of the mysteries surrounding the mechanism of accommodation, and integrate this knowledge into a new consolidated theory of accommodation. 
Accommodation is widely accepted to occur in accordance with the lenticular theory described by von Helmholtz ${ }^{1}$ in 1855. The work of Fincham ${ }^{2}$ and Fisher ${ }^{3}$ support the lenticular theory. Fincham demonstrated the elasticity of the lens capsule and the ability of the lens capsule to "round up" the lens after release of tension on the anterior zonules during ciliary body contraction. ${ }^{2}$ Fisher used new technologies to measure the accommodative system in the laboratory and demonstrated that in vitro lens movements are "solely inherent in the zonule lenticular complex as no vitreous was present in the apparatus." 3 Glasser and $\mathrm{Kaufman}^{4}$ demonstrated relaxation of zonules due to ciliary muscle contraction and felt that zonular relaxation, together with the elastic lens capsule, allows the lens to assume the accommodative state. Their findings support the Helmholtz theory with modifications.

Another major theme in accommodative theory relates to the role of the extralenticular components. This theme has its origins in the "vitreous support" theories of Cramer (1851), Danish ophthalmologist Marius Tscherning ${ }^{6}$ (1900), and, more recently, Koretz and Handleman (1982). ${ }^{7}$ From 1970 through 2001, Coleman ${ }^{8-10}$ developed a catenary/hydraulic support model propounding that the vitreous compartment evidenced by differential pressure measurement between aqueous and vitreous compartments pushes the posterior lens anteriorly and alters the shape of the lens during accommodation. The anatomic basis of Coleman's theory, as well as that of Schachar et al, ${ }^{11}$ conflict with more recent studies by Glasser and Kaufman, ${ }^{4}$ Bernal et al, ${ }^{12}$ Nankivil et al, ${ }^{13}$ and Croft et al. ${ }^{14}$ Finite element analysis ${ }^{15}$ demonstrates that refractive power changes are in accordance with the Helmholtz theory and not in accordance with the Coleman theory. Despite the continuing controversy, the vitreous support concept survives, modified by recent advances in the understanding of the vitreous zonule and its attachments to the vitreous membrane and posterior lens capsule.

The role of the ciliary body, which is the engine of accommodation, has been extensively researched and reviewed by Croft et al, ${ }^{14}$ Stachs et al, ${ }^{16,17}$ Strenk et al,,${ }^{18,19}$ and others with less controversy. Thus, the components of accommodation, including the lens, lens capsule, ciliary body, and vitreous, have been extensively investigated. The persistence of accommodative amplitudes following vitrectomy and in eyes with aniridia is evidence of the nonessential role of the iris and the formed vitreous in accommodation. ${ }^{20}$

The gap in the knowledge of accommodative structures relates to the anatomy of the posterior zonule and their attachments to the anterior vitreous membrane and posterior lens capsule. In the 1970s, Farnsworth and Burke, ${ }^{21}$ Streeten and Pulaski, ${ }^{22,23}$ and Rohen ${ }^{24}$ demonstrated scanning electron microscopy (SEM) of the zonular architecture. Study of the posterior zonular anatomy has been hindered by the collapse of spaces surrounding the posterior zonules and the need to remove the adherent vitreous membrane for SEM which has prevented full understanding of the anatomy of the posterior zonule.

As many investigators have noted, the architecture of the zonules determines the way the forces of ciliary body contraction are distributed in shaping the lens during accommodation and disaccommodation. Glasser ${ }^{25}$ demonstrated the circa-2000 understanding of the anatomy of the zonule in a schematic diagram of the accommodative structures (Figure 1). In 2006, Bernal et al ${ }^{12}$ developed an environmental SEM to image the posterior zonule in human eyes, and they showed that posterior zonular fibers originate from the ciliary body and anchor in the anterior hyaloid membrane and to Weiger's ligament, which attaches the anterior hyaloid membrane in a band around the posterior lens capsule. This confirmed the findings of Albrecht and Eisner, ${ }^{26}$ who, in 1982, identified these fibers as "hyalocapsular" and "hyalociliary" zonule, now considered to be the elements of the anterior division of the vitreous zonule. Other elements of the vitreous zonule include the intermediate and posterior fibers of the vitreous zonule and the pars plana zonules (Figure 2).

The three-dimensional (3D) architecture of the anterior and posterior zonules was studied with SEM by Farnsworth and Burke ${ }^{21}$ in 1977. They identified four tracts of zonules but believed that most zonules passed directly through the ciliary valleys to the pars plana. They noted some zonules inserting into the basement lamina of the ciliary processes and some zonular bundles originating in the basement lamina

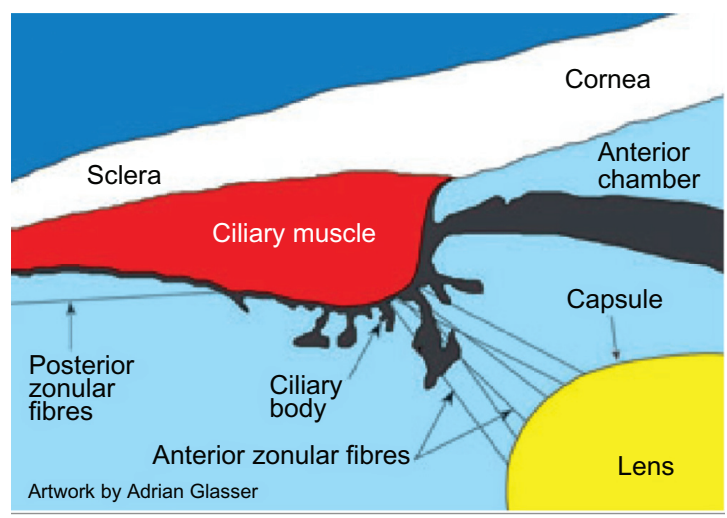

Figure I Schematic diagram showing anatomy of accommodation (Glasser ${ }^{25}$ circa 2000). Glasser shows the pars plana zonule but does not show vitreous zonule. Note: Reproduced with permission of John Wiley \& Sons Ltd from Glasser A. Restoration of accommodation: surgical options for correction of presbyopia. Clin Exp Optom. 2008;91(3):279-295. 


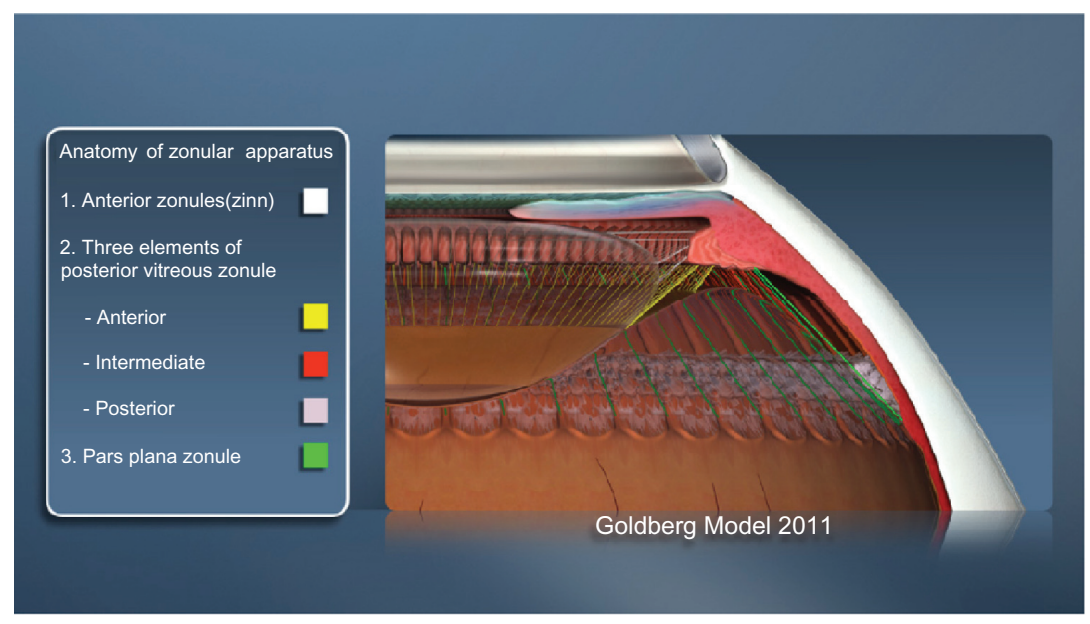

Figure 2 Schematic diagram showing elements of zonular apparatus. All elements of the zonular anatomy and attachments to anterior hyaloid and posterior lens capsule are shown.

of the ciliary process and extending posteriorly to the pars plana. They believed that there are two types of connections between the posterior lens capsule and the ciliary body - (1) a single-segment (lens-to-pars plana without interruption) and (2) a two-segment connection (lens-to-ciliary process and ciliary process-to-pars plana). The single-segment concept of zonular anatomy was held by many, including von Helmholtz ${ }^{1}$ and Coleman. ${ }^{8-10}$

Rohen ${ }^{24}$ in 1979 studied the zonular apparatus in human and monkey eyes. He demonstrated the dividing fork of the pars plana zonules at the posterior end of the ciliary processes and within the ciliary valleys he demonstrated the presence of tension fibers in the ciliary valleys attaching the main fibers of the zonules to the basement membrane of the ciliary processes. Many finer fibers join together in this area, known as the zonular plexus. The zonular plexuses are firmly attached to the bottom of the ciliary valleys, allowing the zonular fiber bundles to change their direction sharply, functioning as a fulcrum. The strength and function of the tension fibers is disputed by Coleman, who believes the zonule is passing through the ciliary valleys and serves as a moving guide or "pylon" to redirect the zonular force on the anterior lens capsule.

In 2010, Lutjen-Drecoll et al (the Croft Study) ${ }^{27}$ reported on the "morphology and accommodative function of the vitreous zonule in human and monkey eyes." This team of German and American researchers used novel SEM techniques and correlated these with ultrasound biomicroscopy (UBM). By doing this, they were able to visualize the anterior, intermediate, and posterior vitreous zonule and their connections to the ciliary body, vitreous membrane, lens capsule, and ora serrata. Their findings have advanced our knowledge of the anatomy of the posterior zonule. They identified the presence of a cleft between the vitreous membrane and the pars plana zonules bridged by zonular fiber bundles called the intermediate vitreous zonule. Each intermediate vitreous zonular fiber splits anteriorly and forms a fork whose tines insert into the zonular plexus on either side of an individual ciliary process. Posteriorly, each intermediate vitreous fiber splits into fibrils that become part of the vitreous membrane. At the site of vitreous attachment to the posterior pars plana and ora region (known as the attachment area), a multilayered interconnected sponge-like ring is formed called the posterior vitreous zonule (Figure 2).

This report presents a computer-animated model of the structures of accommodation based on new understanding of the structures of the zonular apparatus integrated with current understanding of the mechanism of accommodation. Analysis of this model suggests a new, consolidated theory of the mechanism of accommodation, including a new theory of reciprocal zonular action.

\section{Methods}

Models are of central importance in many scientific contexts (eg, double helix model of DNA) and the use of "modelbased reasoning" is an extremely productive method of conceptual change in science. ${ }^{28}$ This report presents a computer-animated model of accommodation along with proposed modifications to the understanding and theory of accommodation.

During the course of clinical research on accommodating intraocular lens (IOL), it was found that building 3D models helped researchers to visualize and understand the variables such as capsular and zonular shape and location 
and shape of IOL fixation, which may influence the function of accommodating IOLs. Inevitably, this led to extensive study of the literature on the mechanism of accommodation and to recognition that there is a gap in the knowledge of the anatomy of the zonule, the role of the zonule in accommodation, and, more specifically, the anatomy and role in accommodation of the vitreous zonule.

\section{Computer-animated model}

The computer-animated model was produced as follows. The 3D model of the eye was created using several combined technical processes along a flexible production pipeline. The half-eye illustration is first modeled from individual polygons in Autodesk ${ }^{\circledR}$ 3D studio MAX $^{\circledR}$ (2012 [64 bit]; Autodesk, Inc, San Rafael, CA), a high-end visual effects and production software package used by a wide range of animation studios. This initial process can be thought of as sculpting in a digital form. Points are pushed, pulled, added, and subtracted until the form is polished and refined. Color shading and lighting are then added to the object. This stage involves the addition of realistic color painting using Adobe ${ }^{\circledR}$ Photoshop (CS5; Adobe Systems Incorporated, San Jose, CA) as well as lighting the object on a digital stage. The final stages of the production pipeline are involved with animation of the half eye. Its form in digital space, as well as location, is animated along paths of varying complexity. As this process is flexible, edits to form, color, lighting, and movement are addressed in an effort to refine exact details of the object. Postproduction processing is addressed in Adobe ${ }^{\circledR}$ After Effects ${ }^{\circledR}$ (CS5; Adobe Systems Incorporated). This software package addresses video editing, timing, and color adjustments to the final rendered animation. The final outcome of this process yields a visually accurate representation of the object in a digital media format, which can be displayed through a wide range of digital outputs. While 3D modeling and animation are useful in reflecting the known world, the true power of the medium is to shine a light on the unknown and newly discovered aspects of our environment.

The 3D animation model was produced in collaboration with an experienced medical animator. UBM was used to help build the model eye: click here to view a UBM file in motion of a 25-year-old eye during accommodation. The anatomic elements of the vitreous zonule were defined by the Croft study ${ }^{27}$ and the remaining anatomic structures derive from extensive review of the literature integrated with findings on UBM, including direct comparison of the UBM in motion with the model eye. The positioning of the structures in accommodation and disaccommodation were modeled and the model was animated. The model is not rectified to scale. Structures are illustrated to demonstrate location and function, with relative size being approximate.

\section{Theory of reciprocal zonular action}

Utilizing model-based reasoning, the mechanism of accommodation will be described and a new consolidated theory of accommodation is presented including a new theory of reciprocal zonular action.

\section{Results}

Click here to access the animated model. An illustration of the structures in accommodation and disaccommodation is shown in Figure 3 without animation.

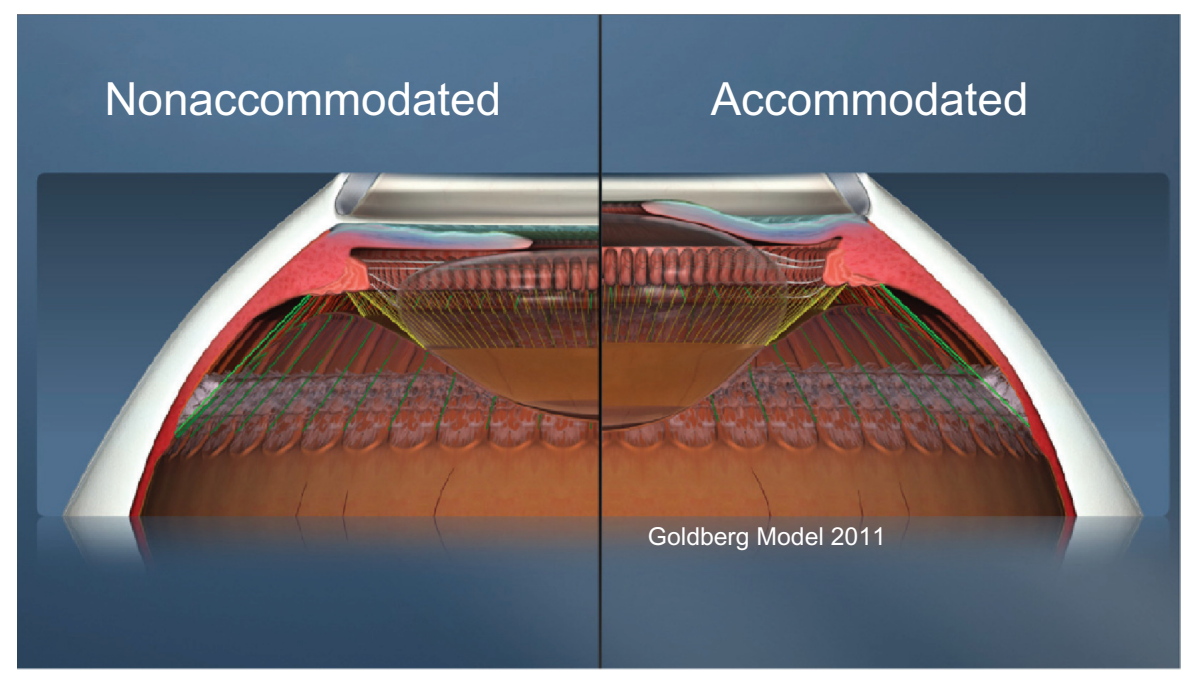

Figure 3 Schematic diagram showing half eye in accommodation and half eye in disaccommodation. Movements of accommodative structures modeled from ultrasound biomicroscopy in motion and recent studies on the anatomy of the vitreous zonule..$^{12,27}$ 


\section{Anatomy of accommodation}

Based on new findings regarding the vitreous zonule and utilizing UBM in motion during accommodation and disaccommodation to help position the anatomic elements, the half-eye illustration demonstrates the components of the anatomy of accommodation (Figure 2). The representations of the cornea, anterior chamber, lens, ciliary body, and ora serrata are well established. The representation of the vitreous zonule and its attachments to the anterior hyaloid are added. A comparison of Figures 1 and 2 demonstrates the change in perspective that these additions accomplish. The earlier schematic allows for a change in lens shape and position as a result of relaxation of the anterior zonules combined with the capsular forces which thicken and "round up" the lens. Add the pars plana zonule, as in the Glasser schematic, and this suggests a mechanism for accommodative stretch on the ciliary body with stored energy for disaccommodation and return of the ciliary body and lens to their nonaccommodative state. Further, add the anterior vitreous zonule fibers, which travel from the zonular plexus in the valley of the pars plicata of the ciliary body to insert in the anterior hyaloid and Weiger's ligament. These fibers are capable of producing traction on the cradle-like attachment of Weiger's ligament, and have the potential to support the lens and contribute to the shape changes of the posterior capsule during accommodation. The intermediate vitreous zonule fibers provide the means for ciliary body contraction to pull the anterior vitreous membrane peripherally at the attachment area above the ora serrata. The attachment zone includes a network of posterior zonules surrounding the pars plana zonules as they insert into the elastic choroid above the ora serrata and very likely acts as a shock absorber dampening and modulating the tension at the posterior anchoring site of the accommodative apparatus.

The anterior hyaloid in this model is more anatomically detailed than prior representations. The anterior hyaloid is attached peripherally at the vitreous base/ora serrata attachment zone and attached centrally via Weiger's ligament to the posterior lens capsule. During accommodation, UBM measurements demonstrate that the distance from the scleral spur to the ora serrata decreases $;{ }^{27}$ therefore the pars plana zonules pull the attachment zone forward while anchored in the elastic choroid. As the anterior hyaloid moves anteriorly at the vitreous base, there is forward traction on the outer edge of the hyaloid as it courses anteriorly in approximation to the pars plicata, hereafter referred to as the shoulder of the anterior hyaloid membrane. The anterior division of the vitreous zonule, previously referred to as hyalocapsular zonule, provides traction to the posterior lens capsule. By viewing the animated model it can be noted that the vectors of the anterior vitreous zonule create mostly angular movement which helps to position the lens and shape the posterior capsule during ciliary body contraction. The topography of the anterior vitreous membrane resembles a diaphragm with a peripheral shoulder and a central concavity following the contour of Weiger's ligament and unattached centrally in Berger's space where the posterior capsule is able to move posteriorly and steepen without traction of the anterior hyaloid. During ciliary body contraction, the vitreous base moves anteriorly, the shoulder moves anteriorly and centripetally, and the central concavity supports and shapes the lens via angular vectors at Weiger's ligament, allowing for posterior movement of the central hyaloid to make space for the thickening of the lens. As such, this model demonstrates that it is the support and movement of the anterior hyaloid that results in changes to the posterior surface of the lens. The absence of formed vitreous, for example, post vitrectomy, does not reduce accommodative amplitudes, ${ }^{20}$ and it is likely that the accommodative mechanism is indifferent to the structure of the vitreous body apart from the anterior hyaloid membrane. This suggests that vitreous support is provided by the anterior vitreous membrane, not by the presence or absence of formed vitreous.

\section{Theory of reciprocal zonular action}

During accommodation, the ciliary body moves forward and centripetally and at the same time the posterior zonular attachments, interconnected with the vitreous membrane and the posterior lens capsule, are also stretched contributing to the shape changes in the lens. There is a reciprocal action of the anterior zonules and the posterior zonules. During ciliary body contraction, the anterior zonules lose tension while the posterior zonules stretch and exert force on the posterior lens capsule, playing a role in shaping the posterior lens thickness and curvature. During ciliary body relaxation, the posterior zonules lose tension as the lens flattens and is pulled back by the increasing tension of the anterior zonules.

\section{Discussion}

This animated model of accommodation enables a new perspective and framework to demonstrate and interpret the mechanism of accommodation. The recent work of Bernal et $\mathrm{al}^{12}$ in demonstrating the hyalocapsular (anterior vitreous) 
zonule, and of Lutjen-Drecoll et $\mathrm{al}^{27}$ in demonstrating the anterior, intermediate, and posterior vitreous zonule fills a gap in the knowledge of the anatomy of accommodation and provides the opportunity to solve some of the mysteries of the mechanism of accommodation.

The continuing debate and controversy over the role of the extralenticular elements in accommodation, including the role of the zonule and the vitreous, may be resolvable. The role of the lens and ciliary body are well established. The refractive changes during accommodation are due to the increased thickness of the lens and the increased curvature of the anterior and posterior capsule. Forces acting on the lens originate in the contraction of the ciliary muscle resulting in anterior and centripetal movement of the ciliary body. While the anterior zonules relax there is traction on the vitreous zonules (anterior, intermediate, and posterior) and pars plana zonules resulting in traction on the anterior vitreous membrane which attaches to the lens in a cradleshaped Weiger's ligament.

The vitreous support concept survives and is addressed by recent studies. Nankivil et $\mathrm{al}^{13}$ demonstrated that the posterior zonules play a significant support role in accommodation. After transection of the anterior zonules, they showed that a significant fraction of accommodative changes in the lens is due to the effect of the posterior zonule. As Fisher ${ }^{3}$ stated in 1982, the accommodative changes in the lens are "inherent in the zonule lenticular complex." Nankivil et $\mathrm{al}^{13}$ posit that an alternative to vitreous support is that the posterior zonules and hyaloid membrane provide the supporting role. This is supported by the finding of retained accommodative amplitudes following vitrectomy. The animated model in this report demonstrates the effects of the posterior zonule, and is in agreement with the findings of Nankivil et $\mathrm{al}^{13}$ and Lutjen-Drecoll et al. ${ }^{27}$ The vitreous support concept should be reformulated to specify "posterior zonule-hyaloid membrane" support.

The work of Coleman ${ }^{8-10}$ has set the stage for further progress in understanding accommodation. Coleman demonstrated a pressure differential between the aqueous and the vitreous compartment, and proposed that accommodative lens changes occurred because of vitreous pressure. This author believes the pressure differential measured by Coleman is created by the ciliary muscle pulling the peripheral hyaloid anteriorly while at the same time storing energy for disaccommodation in the stretched posterior zonules. During ciliary muscle contraction the anterior hyaloid moves forward peripherally, the central concavity of the anterior hyaloid changes the angle and orientation of Weiger's ligament, and axially the unattached anterior hyaloid moves posteriorly. It is important to consider the volume of the aqueous and vitreous compartments which remain stable. The volume of aqueous drainage through Schlemm's canal is compensated for by aqueous production. Thus, the anterior hyaloid moves forward peripherally, and centrally the anterior hyaloid unattached to the posterior capsule in Berger's space moves posteriorly. The hydraulic effects differ from Coleman's model because the anterior hyaloid is pulled forward peripherally by the pars plana and intermediate vitreous zonules, and in the visual axis the anterior hyaloid moves posteriorly to allow space for the thickening lens. As the volume of the vitreous space increases peripherally there is a compensatory decrease in vitreous volume centrally. A similar change in the shape of the aqueous space occurs to compensate for the anterior movement of the lens and shallowing of the central anterior chamber. To compensate, there is a deepening of the anterior chamber peripherally evidenced by posterior bowing of the midperipheral iris during accommodation.

Coleman also believed that the zonules originate in the ora serrata and extend through the valleys of the ciliary processes to be redirected to insert in the lens capsule. Coleman thought the path of the single zonule extending via the anterior zonules to the anterior lens capsule created a catenary shape and that posterior vitreous pressure changes the catenary shape according to his model. This author's model and theory conflicts with the anatomic basis and origin of the pressure differential in Coleman's model. The issue of one segment or two segment posterior zonule anatomy is not resolved. Farnsworth and Burke ${ }^{21}$ thought that most zonules were one segment, although they identified two segment fibers extending from the valleys of the ciliary processes to the lens capsule and from the ciliary processes to the attachment area above the ora serrata. Stachs et $\mathrm{al}^{17}$ found fibers inserting on the anterior and posterior lens capsule emerging anteriorly at the ciliary body. Bernal et $\mathrm{al}^{12}$ noted posterior zonular fibers originating in the ciliary body and inserting into the anterior hyaloid and the attachment zone. Further research is now needed to study the architecture of the ciliary plexus in order to determine if there are both one and two segment zonules. The reciprocal zonular action theory would be supported by the two segment anatomy where the ciliary plexus acts as an insertion for fibers directed to the lens anteriorly and to the anterior hyaloid and ora serrata posteriorly. 
The use of motion in observing the UBM file and the 3D animation demonstrates how the structures interconnect and function as a unit and greatly aid the visualization and understanding of the mechanism of accommodation. There is synchrony and unity of the anatomic elements evident in the animated model. The model is not rectified to scale, and further knowledge of the anatomic structures will enable more precise and more accurate demonstration in the future.

This computer-animated model of accommodation is based on new understanding of the anatomy of the vitreous zonule and attachments to the anterior hyaloid membrane. Interpreting the model with model-based reasoning ${ }^{28}$ suggests a new theory of accommodation including the mechanism of reciprocal zonular action. Further scientific research is needed to validate these concepts. UBM in motion may be useful to demonstrate movement of the anterior hyaloid which could reinforce the proposed mechanism of posterior zonule-hyaloid membrane support. Additional SEM is needed to determine the anatomy of the zonular plexus in order to resolve the issues surrounding one or two segment zonular attachments in the zonular plexus. This theory has many implications for the surgical correction of presbyopia. Lutjen-Drecoll et $\mathrm{al}^{27}$ have demonstrated that lysis of the posterior zonule in a presbyopic animal model results in improvement of the age-related loss of ciliary body movement. This illustrates an extralenticular mechanism of the pathophysiology of presbyopia, as well as a therapeutic target for presbyopia surgery. Further, the demonstration of a decrease in the diameter of the ciliary sulcus during accommodation suggests that ciliary sulcus fixation leaving an intact posterior capsule for support for accommodating IOLs could improve results. In order to move forward, it is hoped that this model and theory will be validated and tested by the scientific community.

\section{Acknowledgments}

Evan Patrick of EyeMaginations provided his skill as a medical animator and his contribution is integral to this work - many thanks. This work would not be possible without standing on the shoulders of the many giants in the field who have researched the mechanism of accommodation. As a clinical ophthalmologist I am humbled by the opportunity to make a contribution.

\section{Disclosure}

The author reports no conflicts of interest in this work.

\section{References}

1. von Helmholtz H. Über die akkommodation des auges [On the accommodation of the eye]. Albrecht Von Graefes Arch Klin Exp Ophthalmol. $1855 ; 1: 1-74$.

2. Fincham EF. The mechanism of accommodation. Br J Ophthalmol Monogr. 1937;8:7-76.

3. Fisher RF. The vitreous and lens in accommodation. Trans Ophthalmol Soc UK. 1982;102 Pt 3:318-322.

4. Glasser A, Kaufman PL. The mechanism of accommodation in primates. Ophthalmology. 1999;106(5):863-872.

5. Cramer A. Tijdschrift der maatschappij vor geneeskunde [Journal of the society of medicine]. Nederlandisch Lancet. 1851;1:529-541. [Dutch.]

6. Tscherning M. Physiologic Optics. Weiland C, trans. Philadelphia, PA: Keystone Publishing Company; 1900.

7. Koretz JF, Handleman GH. Model of the accommodative mechanism in the human eye. Vision Res. 1982;22(8):917-927.

8. Coleman DJ. Unified model for accommodative mechanism. Am J Ophthalmol. 1970;69(6):1063-1079.

9. Coleman DJ. On the hydraulic suspension theory of accommodation. Trans Am Ophthalmol Soc. 1986;84:846-868.

10. Coleman DJ, Fish SK. Presbyopia, accommodation and the mature catenary. Ophthalmology. 2001;108(9):1544-1551.

11. Schachar RA, Black TD, Kash RL, Cudmore DP, Schanzlin DJ. The mechanism of accommodation and presbyopia in the primate. Ann Ophthalmol. 1995;27:58-67.

12. Bernal A, Parel JM, Manns F. Evidence for posterior zonular fiber attachment on the anterior hyaloid membrane. Invest Ophthalmol Vis Sci. 2006;47(11):4708-4713.

13. Nankivil D, Manns F, Arrieta-Quitero E, et al. Effect of anterior zonule transection on the change in lens diameter and power in cynomolgus monkeys during simulated accommodation. Invest Ophthalmol Vis Sci. 2009;50(8):4017-4021.

14. Croft MA, Glasser A, Heatley G, et al. Accommodative ciliary body and lens function in rhesus monkeys, I: normal lens, zonule and ciliary process configuration in the iridectomized eye. Invest Ophthalmol Vis Sci. 2006;47(3):1076-1086.

15. Martin H, Guthoff R, Terwee T, Schmitz KP. Comparison of the accommodation theories of Coleman and of Helmholtz by finite element simulation. Vision Res. 2005;45(22):2910-2915.

16. Stachs O, Martin H, Kirchoff A, Stave J, Terwee T, Guthoff R. Monitoring accommodative ciliary muscle function using threedimensional ultrasound. Graefes Arch Clin Exp Ophthalmol. 2002;240(11):906-912.

17. Stachs O, Martin H, Behrend D, Schmitz KP, Guthoff R. Threedimensional ultrasound biomicroscopy, environmental and conventional scanning electron microscopy, investigations of the human zonula ciliaris for numerical modeling of accommodation. Graefes Arch Clin Exp Ophthalmol. 2006;244(7):836-844.

18. Strenk SA, Semmlow JL, Strenk LM, Munoz P, Gronlund-Jacob J, DeMarco JK. Age related changes in human ciliary muscle and lens: a magnetic resonance imaging study. Invest Ophthalmol Vis Sci. 1999; 40(6):1162-1169.

19. Strenk SA, Strenk LM, Guo S. Magnetic resonance imaging of the antero-posterior position and thickness of the aging, accommodating, phakic, and pseudophakic ciliary muscle. J Cataract Refract Surg. 2010;36(2):235-241.

20. Fisher RF. Is the vitreous necessary for accommodation in man? $\mathrm{Br} J$ Ophthalmol. 1983;67(3):206.

21. Farnsworth PN, Burke P. Three-dimensional architecture of the suspensory apparatus of the lens of the rhesus monkey. Exp Eye Res. 1977; 25(6):563-576.

22. Streeten BW. The zonular insertion: a scanning electron microscopic study. Invest Ophthalmol Vis Sci. 1977;16(4):364-375.

23. Streeten BW, Pulaski JP. Posterior zonules and lens extraction. Arch Ophthalmol. 1978;96(1):132-138. 
24. Rohen JW. Scanning electron microscopic studies of the zonular apparatus in human and monkey eyes. Invest Ophthalmol Vis Sci. 1979;18(2):133-144.

25. Glasser A. Restoration of accommodation: surgical options for correction of presbyopia. Clin Exp Optom. 2008;91(3):279-295.

26. Albrecht M, Eisner G. The hyalo-capsular zonula. Graefes Arch Clin Exp Ophthalmol. 1982;218(2):88-92.
27. Lutjen-Drecoll E, Kaufman PL, Wasielewski R, Ting-Li L, Croft MA. Morphology and accommodative function of the vitreous zonule in human and monkey eyes. Invest Ophthalmol Vis Sci. 2010;51(3):1554-1564.

28. Nersessian NJ. Model-based reasoning in conceptual change. In: Magnani L, Nersessian NJ, Thagard P, editors. Model-based Reasoning in Scientific Discovery. New York, NY: Kluwer Academic/Plenum Publishers; 1999:5-23.
Clinical Ophthalmology

\section{Publish your work in this journal}

Clinical Ophthalmology is an international, peer-reviewed journal covering all subspecialties within ophthalmology. Key topics include: Optometry; Visual science; Pharmacology and drug therapy in eye diseases; Basic Sciences; Primary and Secondary eye care; Patient Safety and Quality of Care Improvements. This journal is indexed on

\section{Dovepress}

PubMed Central and CAS, and is the official journal of The Society of Clinical Ophthalmology (SCO). The manuscript management system is completely online and includes a very quick and fair peer-review system, which is all easy to use. Visit http://www.dovepress.com/ testimonials.php to read real quotes from published authors. 